ORIGINAL ARTICLE

\title{
Lymphohaematopoietic cancer risk among chemical workers exposed to benzene
}

\author{
L J Bloemen, A Youk, T D Bradley, K M Bodner, G Marsh
}

Occup Environ Med 2004;61:270-274. doi: 10.1136/oem.2003.007013

See end of article for authors' affiliations

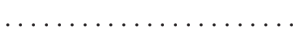

Correspondence to: Dr L Bloemen, Dow Benelux NV, PO Box 48 4530 AA Terneuzen, Netherlands; libloemen@ dow.com

Accepted 17 June 2003

\begin{abstract}
Aims: To determine cause specific mortality in a cohort of 2266 chemical workers exposed to benzene in various manufacturing processes after 1935.

Methods: The cohort has accumulated over 80000 person-years of observation; about $70 \%$ of the workers were followed for more than 30 years since first exposure.

Results: Mortality from non-malignant diseases of the blood was increased (SMR 2.17, 95\% Cl 0.87 to 4.48), and correlated with duration of benzene exposure, although risk had decreased from the previous investigation of this cohort. The risk for leukaemia was slightly above background (SMR 1.14, obs 12, 95\% $\mathrm{Cl} 0.59$ to 1.99) but has also decreased since the earlier study of this cohort. SMRs for acute nonlymphocytic leukaemia (ANLL), chronic lymphatic leukaemia, and non-Hodgkin's lymphoma were 1.11, 0.42 , and 1.06 respectively. There was evidence of a weak trend of increasing SMRs for leukaemia and possibly ANLL with increasing low-level cumulative exposure but not with other measures.

Conclusion: Leukaemia and ANLL results were consistent with the mildly increased risk estimates from lower exposure subgroups of the Pliofilm cohort.
\end{abstract}

$\mathrm{T}$ he strongest evidence that benzene causes acute nonlymphocytic leukaemia (ANLL) or the slightly narrower category acute myeloid leukaemia (AML) is based on one large study with high exposures. ${ }^{1}$ Researchers still debate whether peak or continuous exposures are more potent in inducing ANLL. Recently, Rushton and Romaniuk ${ }^{2}$ found that indices of peak exposure explained the increase in AML better, while the data presented by Ireland and colleagues ${ }^{3}$ failed to show an increased risk for leukaemia for those jobs classified as having only high intermittent benzene exposure.

Other studies have indicated that multiple myeloma (MM) and non-Hodgkin's lymphoma (NHL) may also be related to benzene exposure, ${ }^{45}$ but the published literature is inconsistent. ${ }^{36-9}$ Studies of workers at low benzene exposure levels have produced inconsistent findings for all cancer sites. ${ }^{2}{ }^{10-12}$

Researchers from The Dow Chemical Company were among the first to report on possible health effects related to benzene exposure. Townsend and colleagues ${ }^{13}$ published health examination findings, and Ott and colleagues ${ }^{14}$ published mortality data for Dow Chemical Michigan Operations employees exposed to benzene. Biomonitoring as a method to assess exposure to benzene had been already evaluated by Dow scientists one year earlier. ${ }^{15}$

The original mortality investigation of this cohort studied 594 people working in chlorobenzol, alkylbenzene, and ethylcellulose production areas between 1938 and 1970, with follow up from 1940 to 1973. In a later update, Bond and colleagues ${ }^{16}$ extended the period of observation through 1982.

We report the 1940-96 mortality experience of benzene exposed workers at the same manufacturing site. This new update extends the previous observation period by an additional 14 years and captures data from previous unstudied low benzene exposure production areas.

\section{METHODS}

\section{Definition of the study cohort}

Ott and colleagues ${ }^{14}$ and Bond and colleagues ${ }^{16}$ have described details of cohort identification. In brief, the previous update used cross-sectional census lists to enumerate employees with at least one month's work experience in any of three relevant production areas of Michigan Operations on or after 1 January 1938. In the chlorobenzol area, only those jobs with benzene exposures of 2-9 ppm TWA, the highest for this area, had been considered. Chlorobenzol and alkylbenzene operations ceased in 1978, and benzene use in ethylcellulose production was discontinued in 1977.

Subsequent to the identification of the original benzene cohort, the Epidemiology Department of Dow Chemical has improved its employee registry by inputting complete work history information on all employees employed in the United States based manufacturing operations, starting in 1940. To identify additional eligible subjects for this study, the cohort was re-enumerated by applying the original inclusion criteria to this new database with detailed and complete work history records. Persons employed in the chlorobenzol area with jobs in the lowest exposure category are now included in the cohort. For each employee, person-years at risk for mortality were accumulated until date of death, date lost to follow up, or the end of the study period, 31 December 1996, whichever occurred first.

Vital status and cause of death were derived from the company's research database, which is regularly updated with data from company human resource records, the National Death Index, state vital statistics bureaus, and other sources. Cause of death was coded by a certified nosologist according to the International Classification of Diseases (ICD) in effect at the time of death. For the analysis all codes were then converted to the 9th revision (ICD-9).

\section{Exposure assessment}

In the chlorobenzol process, benzene is reacted to produce mono- and dichlorobenzene. The unreacted benzene is recycled early in the cycle, resulting in low exposure potential

Abbreviations: AML, acute myeloid leukaemia; ANLL, acute nonlymphocytic leukaemia; CLL, chronic lymphatic leukaemia; MM, multiple myeloma; NHL, non-Hodgkin's lymphoma; SMR, standardised mortality ratio 
in later steps. The operations started in 1920. Measurements of ambient benzene levels were available from the start up of the plant in 1944. The alkylbenzene area manufactured mainly styrene via alkylation of benzene. Operations started in 1935 and industrial hygiene measurements of airborne benzene are available since 1953. The ethylcellulose unit started up in 1936; it used benzene as a solvent. The process included loading and unloading of batch reactors which contributed to high benzene exposures. Initial high exposures for some jobs in this area were mediated by engineering changes.

Based on industrial hygiene measurements, jobs in the original study ${ }^{14}$ were assigned to one of four time weighted average exposure categories: very low $(<2 \mathrm{ppm}$, average $1 \mathrm{ppm})$, low (2-9 ppm, average $5 \mathrm{ppm})$, moderate (10$24 \mathrm{ppm}$, average $15 \mathrm{ppm})$, and high $(25+\mathrm{ppm}$, average $30 \mathrm{ppm})$. For the current update, a certified industrial hygienist familiar with the relevant production areas reassessed all jobs using the original categories except the "very low" category. This was split at 1 ppm. No differences were seen in individual exposure estimates compared to the previous study.

Individual employee work histories were linked to job and time specific benzene exposure estimates to compute summary exposure measures. We used three such measures to evaluate risk: (1) duration of exposure is the cumulative time (years) spent in jobs with non-zero exposure; (2) cumulative exposure (ppm-years) is the cumulative product of days in each job and the estimated average daily exposure to benzene divided by 365.25 ; and (3) average intensity of exposure (ppm) is the ratio of cumulative exposure to duration of exposure. Each exposure measure was categorised at three levels, chosen so as to include one third of all leukaemia cases at each level of cumulative exposure. Personyears for computing exposure indexes includes the time workers were exposed prior to meeting the criteria for entry into the cohort.

\section{Statistical analysis}

We used a modified life table procedure (Occupational Cohort Mortality Analysis Program, OCMAP-PLUS ${ }^{17}$ to examine the total and cause specific mortality of the cohort from I January 1940 to 31 December 1996. Using an OCMAPPLUS modified life table procedure, the person-years at risk contributed by each study member were jointly classified by the primary study factors race (white, non-white), sex (male, female), calendar time (1940-54, 1955-59, 1960-64, 1965-69, 1970-74, 1975-79, 1980-84, 1985-89, 1990-96) and age group $(<5,5-9,10-14,15-19,20-24,25-29, \ldots ., 75-79,80-84$, $85+)$. For each study member, person-years at risk began on the date on which one month of cumulative service in (post1937) benzene related jobs was achieved or 1 January 1940, whichever was later. Person-years at risk for mortality were accumulated until date of death, date of loss to follow up, or the end of the study period (31 December 1996), whichever occurred first.

Cumulative exposure was calculated as the product of the number of days in each job and the estimated average daily exposure to benzene (in ppm-years). The 39.7 ppm-years is the average estimate of cumulative exposure computed as of the end of follow up for all workers. This is not a measure of average intensity, rather it is an average of the cumulative exposure values for all workers at the end of their work history.

Expected numbers of deaths were computed from population death rates provided by the Mortality and Population Data System (MPDS) maintained at the University of Pittsburgh. ${ }^{18}$ In addition to US death rates, local death rates were derived for the combined populations of the six county area from which the workforce was largely drawn (Midland, Bay, Isabella, Gratiot, Saginaw, Gladwin). Statistics were generated from 1940 onwards for malignant causes and 1960 onward for non-malignant causes of death.

Mortality excesses and deficits were expressed as standardised mortality ratios (SMRs) and their associated 95\% confidence intervals (CI). The latter were derived using Poisson probabilities. ${ }^{19}$

A 15 year lag period was used to test the association of non-malignant blood diseases and lymphohaematopoietic cancers with cumulative exposure to benzene. Lagging of exposure was used to isolate those exposure periods most relevant to aetiology, in an attempt to model potential disease latency. The use of a 15 year lag period is suggested by the Pliofilm cohort investigation. ${ }^{20}$

\section{RESULTS}

The cohort includes 2266 members who worked for more than one month in benzene exposed jobs, and who contributed 82411 person-years. About two thirds (68\%) were followed for at least 30 years. The cohort is predominantly white $(99.5 \%)$ and mostly male $(94 \%)$. Nearly half $(47 \%)$ were hired in the decade following 1940. A large portion were short term workers: $42 \%$ worked less than a year and only $26 \%$ worked five or more years.

Fifty nine per cent of the cohort worked in the ethyl cellulose area where benzene was used as a solvent. The average duration of exposure to benzene was 4.8 years (range 3 months to 45 years), average cumulative exposure was 39.7 ppm-years (range 0.05-852 ppm-years), and average intensity of exposure to benzene was $9.6 \mathrm{ppm}$ (range 0.5$35 \mathrm{ppm}$ ). There were no notable differences between the 939 workers who were members of the cohort defined by Bond and colleagues $^{16}$ and the 1327 newly identified cohort members for any of the demographic and exposure variables considered (data not shown).

A total of 1054 deaths were identified among 2266 employees (46\%) as of 31 December 1996, and only 13 study members $(0.6 \%)$ had unknown vital status. Table 1 presents overall SMRs for the cohort using US comparisons. Benzene workers experienced $10 \%$ fewer overall deaths than expected. Comparisons using local county data produced similar results (data not shown). The risk estimate for non-malignant diseases of blood and blood forming organs was greater than expected, SMR 2.17 (95\% CI 0.87 to 4.48 ). One fourth of all deaths were due to malignancies, almost exactly the number expected (SMR 0.97, 95\% CI 0.86 to 1.09). No remarkable increases in risk were seen for any malignant causes considered. Fewer than expected deaths occurred from MM ( 3 observed, 4.2 expected) and chronic lymphatic leukaemia (CLL; 1 observed, 2.4 expected). Risk estimates for NHL, leukaemia, and ANLL were slightly increased (1.06, 1.14, 1.11, respectively). No notable differences in mortality were seen between the members of the original cohort and those newly identified in this study.

Analyses by duration of exposure, cumulative exposure, and average intensity are shown in table 2 for selected causes. The risk for non-malignant diseases of the blood appeared to increase with increasing duration of benzene exposure. The monotonic pattern did not persist for the other two exposure measures; however, the highest SMRs were associated with the highest exposure class. For leukaemia mortality and its subset, ANLL, SMRs increased in magnitude with cumulative exposure, whereas the other two exposure measures showed indistinct patterns. Results for ANLL are particularly difficult to interpret due to the small number of deaths. NonHodgkin's lymphoma mortality displayed no remarkable trends with exposure. 
Table 1 Observed deaths and SMRs for selected causes of death among benzene exposed chemical workers, compared to the US population†

\begin{tabular}{|c|c|c|c|}
\hline Cause of death (9th revision) & Deaths & SMR & $95 \% \mathrm{Cl}$ \\
\hline All causes of death (001-999) & 972 & $0.90^{* *}$ & 0.85 to 0.96 \\
\hline All malignant neoplasms (140-208) & 278 & 0.97 & 0.86 to 1.09 \\
\hline Digestive organs and peritoneum (150-159) & 65 & 0.90 & 0.70 to 1.15 \\
\hline Bronchus, trachea, and lung (162) & 97 & 1.00 & 0.81 to 1.21 \\
\hline Prostate (185) & 22 & 0.95 & 0.59 to 1.43 \\
\hline Kidney (189.0, 189.1, 189.2) & 8 & 1.16 & 0.50 to 2.29 \\
\hline Bladder and other urinary $(188,189.3,189.4,189.8,189.9)$ & 3 & 0.39 & 0.08 to 1.14 \\
\hline Malignant melanoma of skin (172) & 5 & 1.27 & 0.41 to 2.97 \\
\hline Central nervous system $(191,192)$ & 7 & 0.93 & 0.37 to 1.92 \\
\hline All lymphatic and haematopoietic tissue (200-208) & 27 & 1.01 & 0.66 to 1.46 \\
\hline Non-Hodgkin's lymphoma (200.0-200.8, 202.0, 202.8) & 10 & 1.06 & 0.51 to 1.95 \\
\hline Hodgkin's disease (201) & 2 & 1.01 & 0.12 to 3.63 \\
\hline Multiple myeloma (203) & 3 & 0.72 & 0.15 to 2.10 \\
\hline Leukaemia and aleukaemia (204-208) & 12 & 1.14 & 0.59 to 1.99 \\
\hline Chronic lymphatic leukaemia (204.1) & 1 & 0.42 & 0.01 to 2.36 \\
\hline Acute non-lymphocytic leukaemia (205.0, 206.0, 207.0) & 4 & 1.11 & 0.30 to 2.83 \\
\hline Diseases of blood and blood forming organs (280-289) & 7 & 2.17 & 0.87 to 4.48 \\
\hline Cerebrovascular disease $(430-438)$ & 52 & 0.84 & 0.63 to 1.11 \\
\hline All heart diseases $(390-398,402,404,410-429)$ & 380 & $0.90^{*}$ & 0.81 to 0.99 \\
\hline Non-malignant respiratory disease (460-519) & 74 & 0.85 & 0.67 to 1.07 \\
\hline All external causes (800-999) & 50 & 0.79 & 0.59 to 1.04 \\
\hline
\end{tabular}

†Non-malignant causes: 1960-96, 2171 workers, 60506 person-years at risk. Malignant causes: 1940-96, 2266 workers, 82411 person-years at risk. ${ }^{*} p<0.05 ;{ }^{* *} p<0.01$.

Table 2 Observed deaths and SMRs by benzene exposure measures for selected causes of death, benzene exposed chemical workers, US comparisons

\begin{tabular}{|c|c|c|c|c|c|c|c|}
\hline \multirow[b]{2}{*}{ Exposure measure } & & \multicolumn{3}{|c|}{0 year lag } & \multicolumn{3}{|c|}{15 year lag } \\
\hline & & Obs & SMR & $95 \% \mathrm{Cl}$ & Obs & SMR & $95 \% \mathrm{Cl}$ \\
\hline \multicolumn{8}{|c|}{ Diseases of the blood and blood forming organs } \\
\hline \multirow[t]{3}{*}{ Duration (y) } & $<5$ & 4 & 1.88 & 0.51 to 4.82 & 4 & 1.80 & 0.49 to 4.62 \\
\hline & $5-9$ & 1 & 2.48 & 0.06 to 13.84 & 1 & 2.50 & 0.06 to 13.92 \\
\hline & $10+$ & 2 & 2.90 & 0.35 to 10.48 & 2 & 3.33 & 0.40 to 12.02 \\
\hline \multirow{3}{*}{$\begin{array}{l}\text { Cumulative exposure } \\
\text { (ppm-years) }\end{array}$} & $<28.3$ & 5 & 2.53 & 0.82 to 5.91 & 5 & 2.46 & 0.80 to 5.73 \\
\hline & $28.3-79.1$ & 0 & 0.00 & 0.00 to 5.72 & 0 & 0.00 & 0.00 to 5.93 \\
\hline & $79.1+$ & 2 & 3.33 & 0.40 to 12.04 & 2 & 3.56 & 0.43 to 12.86 \\
\hline \multirow[t]{3}{*}{ Average intensity (ppm) } & $<5$ & 3 & 2.42 & 0.50 to 7.08 & 5 & 1.76 & 0.57 to 4.10 \\
\hline & $5-14$ & 1 & 1.02 & 0.03 to 5.69 & 2 & 5.68 & 0.69 to 20.54 \\
\hline & $15+$ & 3 & 2.99 & 0.62 to 8.74 & 0 & 0.00 & 0.00 to 182.44 \\
\hline \multicolumn{8}{|c|}{ Leukaemia and aleukaemia } \\
\hline \multirow[t]{3}{*}{ Duration (y) } & $<5$ & 5 & 0.70 & 0.23 to 1.63 & 6 & 0.78 & 0.29 to 1.70 \\
\hline & $5-9$ & 4 & 3.09 & 0.84 to 7.90 & 3 & 2.51 & 0.52 to 7.34 \\
\hline & $10+$ & 3 & 1.44 & 0.30 to 4.20 & 3 & 1.84 & 0.38 to 5.38 \\
\hline \multirow{3}{*}{$\begin{array}{l}\text { Cumulative exposure } \\
\text { (ppm-years) }\end{array}$} & $<340$ & 4 & 0.60 & 0.16 to 1.54 & 5 & 0.69 & 0.23 to 1.62 \\
\hline & $28.3-79.1$ & 4 & 2.00 & 0.54 to 5.11 & 3 & 1.71 & 0.35 to 5.00 \\
\hline & $79.1+$ & 4 & 2.16 & 0.59 to 5.53 & 4 & 2.55 & 0.70 to 6.54 \\
\hline \multirow[t]{3}{*}{ Average intensity (ppm) } & $<5$ & 3 & 0.75 & 0.16 to 2.20 & 9 & 0.95 & 0.44 to 1.81 \\
\hline & $5-14$ & 5 & 1.57 & 0.51 to 3.66 & 3 & 2.96 & 0.61 to 8.64 \\
\hline & $15+$ & 4 & 1.19 & 0.32 to 3.05 & 0 & 0.00 & 0.00 to 60.93 \\
\hline \multicolumn{8}{|c|}{ Acute non-lymphocytic leukaemia } \\
\hline \multirow[t]{3}{*}{ Duration (y) } & $<5$ & 2 & 0.82 & 0.10 to 2.97 & 3 & 1.18 & 0.24 to 3.46 \\
\hline & $5-9$ & 1 & 2.20 & 0.06 to 12.23 & 0 & 0.00 & 0.00 to 8.33 \\
\hline & $10+$ & 1 & 1.37 & 0.03 to 7.66 & 1 & 1.58 & 0.04 to 8.79 \\
\hline & $<28.3$ & 2 & 0.87 & 0.11 to 3.13 & 3 & 1.26 & 0.26 to 3.69 \\
\hline \multirow{2}{*}{ (ppm-years) } & $28.3-79.1$ & 1 & 1.47 & 0.04 to 8.17 & 0 & 0.00 & 0.00 to 5.65 \\
\hline & $79.1+$ & 1 & 1.61 & 0.04 to 8.95 & 1 & 1.71 & 0.04 to 9.51 \\
\hline \multirow[t]{3}{*}{ Average intensity (ppm) } & $<5$ & 0 & 0.00 & 0.00 to 2.64 & 3 & 0.93 & 0.19 to 2.73 \\
\hline & $5-14$ & 3 & 2.66 & 0.55 to 7.76 & 1 & 2.65 & 0.07 to 14.74 \\
\hline & $15+$ & 1 & 0.92 & 0.02 to 5.13 & 0 & 0.00 & 0.00 to 146.28 \\
\hline \multicolumn{8}{|l|}{ Non-Hodgkin's lymphoma } \\
\hline \multirow[t]{3}{*}{ Duration (y) } & $<5$ & 6 & 0.93 & 0.34 to 2.02 & 6 & 0.87 & 0.32 to 1.88 \\
\hline & $5-9$ & 1 & 0.88 & 0.02 to 4.88 & 1 & 0.92 & 0.02 to 5.11 \\
\hline & $10+$ & 3 & 1.67 & 0.34 to 4.88 & 3 & 2.15 & 0.44 to 6.28 \\
\hline \multirow{3}{*}{$\begin{array}{l}\text { Cumulative exposure } \\
\text { (ppm-years) }\end{array}$} & $<8.3$ & 8 & 1.31 & 0.57 to 2.58 & 8 & 1.23 & 0.53 to 2.42 \\
\hline & $28.3-79.1$ & 2 & 1.15 & 0.14 to 4.16 & 2 & 1.28 & 0.16 to 4.64 \\
\hline & $79.1+$ & 0 & 0.00 & 0.00 to 2.34 & 0 & 0.00 & 0.00 to 2.75 \\
\hline \multirow[t]{3}{*}{ Average intensity (ppm) } & $<5$ & 6 & 1.67 & 0.61 to 3.64 & 10 & 1.18 & 0.56 to 2.17 \\
\hline & $5-14$ & 2 & 0.69 & 0.08 to 2.48 & 0 & 0.00 & 0.00 to 4.21 \\
\hline & $15+$ & 2 & 0.68 & 0.08 to 2.47 & 0 & 0.00 & 0.00 to 78.26 \\
\hline
\end{tabular}


Lagging exposure by 15 years did not seem to markedly strengthen any of the individual risk estimates or trends with exposure, as would be expected for diseases with characteristic latency periods.

\section{DISCUSSION AND CONCLUSIONS}

This updated and expanded cohort study benefits from long and relatively complete follow up and well characterised exposure estimates. On the other hand, data on peak exposures were too sparse to be useful, and the scarcity of deaths from some key causes, such as ANLL, limited the inferences we might draw from the results.

The highest SMR in this investigation was attributed to non-malignant diseases of the blood (SMR 2.17, 95\% CI 0.87 to 4.48 ), but this estimate has declined markedly since the previous investigation ${ }^{16}$ (SMR 4.44, 95\% CI 0.88 to $12.52,3$ cases). An earlier study of a subgroup of the cohort ${ }^{13}$ found no adverse effects in peripheral blood counts as performed during routine health examinations. Two of the three cases in the cohort of Bond and colleagues (one pernicious anaemia and one aplastic anaemia) were excluded from the current analyses because their deaths occurred prior to 1960, the early limit of the MPDS population rate data. Six other cases were added since the previous update. The current seven deaths included two myelofibroses, two unspecified anaemias, and one case each of aplastic anaemia, leucopenia, and coagulopathy.

The update by Bond and colleagues ${ }^{16}$ showed an increase in leukaemia risk, though based on only four observed deaths (SMR 1.94, 95\% CI 0.52 to 4.88 ). With triple the number of leukaemia deaths in the current study, the risk estimate has declined markedly, and is now only slightly above background levels (SMR 1.14, 95\% CI 0.59 to 1.99). Risk estimates for ANLL and NHL were smaller yet (SMR 1.11, 95\% CI 0.30 to 2.83 ; SMR $1.06,95 \%$ CI 0.51 to 1.95 , respectively). Deaths from the other relevant disease categories, CLL and MM, were fewer than expected.

With respect to exposure trends, mortality from diseases of the blood was correlated with increasing exposure duration and may be associated with high levels of cumulative or average intensity of exposure. On the other hand, leukaemia and ANLL showed weak increases with cumulative exposure but not the other measures, and NHL showed no clear patterns.

An average cumulative exposure of 39.7 ppm-years and an average intensity $9.6 \mathrm{ppm}$ positions this study above those of refinery and distribution workers, but on the very lowest exposure grouping of the Pliofilm cohort.

The mean cumulative exposure for cases and controls in the study on marketing and distribution workers in the UK is 4.6 ppm-years. ${ }^{2}$ The risk for acute myeloid and monocytic leukaemia, a disease category similar to ANLL, is 2.38 in the highest of the quintiles for cumulative exposure, higher or above 4.79 ppm-years. This is above the risk of 0.87 seen in this study for the lowest category, $<27.8$ ppm-years. Also, our risk estimates for ANLL are considerably lower than those seen in the study on Chinese workers in the benzene exposure categories comparable to ours. ${ }^{10}$

An early meta-analysis of petroleum workers ${ }^{21}$ produced a meta-SMR of 1.12 for all leukaemia, but since that time, many of the component investigations have been updated, yielding reduced risk estimates. A more recent meta-analysis showed an SMR of 0.96 for AML. ${ }^{22}$ Average benzene exposures have been estimated to be below $1 \mathrm{ppm}$ for refinery workers, ${ }^{23}$ and somewhat higher for brief periods for distribution workers. ${ }^{24} 25$

Schnatter and colleagues ${ }^{12}$ addressed long term average exposures among Pliofilm workers, using four differing exposure models. Regardless of the model, exposures of less than 20 ppm were associated with only background levels of leukaemia. No cases of ANLL were detected among workers exposed at that level. Crump ${ }^{2026}$ examined cumulative exposure in the same cohort. Risk for ANLL increased dramatically over 400 ppm-years of exposure, and for all leukaemia, over 1000 ppm-years. SMRs were lower at lower cumulative exposure levels (0-45 ppm-years: leukaemia relative risk 1.2, 3 cases; ANLL relative risk 0-2.4, 0-2 cases, due to uncertain cell type; 45-400 ppm-years: leukaemia relative risk 2.7, 4 cases; ANLL relative risk 2.0, 1 case).

Risk estimates from our study do not differ markedly from either of the above industries in terms of average exposures. With respect to cumulative exposure, our cohort experienced risks similar to the lowest exposure groupings of the Pliofilm cohort, considered by some to be below an effect threshold. At those levels, we had more cases to analyse, although the small number of ANLL cases makes comparisons tenuous. Data from our study display signs of a weak trend of leukaemia and possibly ANLL at low levels of cumulative exposure. Because the cumulative exposure categories of the Pliofilm cohort are wider, the same low level trends cannot be examined adequately.

\section{ACKNOWLEDGEMENTS}

The expert assistance of Brenda Jammer, Jean Cartmill, and Monica Chau is greatly appreciated.

\section{Authors' affiliations}

L J Bloemen, Dow Benelux N.V., Epidemiology, Neely Building, Terneuzen, Netherlands

A Youk, GSPH, Department of Biostatistics, University of Pittsburgh, 130 DeSoto Street, Pittsburgh, PA 15261, USA

T D Bradley, The Dow Chemical Company, Global Ind. Hygiene Expertise Center, 1803 Building, Midland, MI 48674, USA

K M Bodner, G Marsh, The Dow Chemical Company, Epidemiology, 1803 Building, Midland, MI 48674, USA

\section{REFERENCES}

1 Rinsky RA, Young RJ, Smith AB. Leukemia in benzene workers. Am J Ind Med $1981 ; 2: 217-45$.

2 Rushton L, Romaniuk H. A case-control study to investigate the risk of leukemia associated with exposure to benzene in petroleum marketing and distribution workers in the United Kingdom. Occup Environ Med 1997;54:152-66.

3 Ireland B, Collins JJ, Buckley CF, et al. Cancer mortality among workers with benzene exposure. Epidemiology 1997;8:318-20.

4 Decouflé P, Blattner WA, Blair A. Mortality among workers exposed to benzene and other agents. Environ Res 1983;30:16-25.

5 Yin SN, Hayes RB, Linet MS, et al. A cohort study of cancer among workers exposed to benzene in China: overall results. Am J Ind Med 1996;29:227-35.

6 Bezabeh S, Engel A, Morris CB. Does benzene cause multiple myeloma? An analysis of the published case-control literature. Environ Health Perspect 1996;104(suppl 6):1393-8.

7 Hotz P, Lauwerys RR. Hematopoietic and lymphatic malignancies in vehicle mechanics. Crit Rev Toxicol 1997;27:443-94.

8 Järvholm B, Mellblom B, Norrman R, et al. Cancer incidence of workers in the Swedish petroleum industry. Occup Environ Med 1997;54:686-91.

9 Savitz DA, Andrews KW. Review of epidemiologic evidence on benzene and lymphatic and hematopoietic cancers. Am J Ind Med 1997;31:287-95.

10 Hayes RB, Yin SN, Dosemeci M, et al. Benzene and the dose related incidence of hematologic neoplasms in China. J Natl Cancer Inst 1997;89:1065-71.

11 Schnatter AR, Armstrong TW, Thompson LS, et al. The relationship between low-level benzene exposure and leukemia in Canadian petroleum distribution workers. Environ Health Perspect 1996;104(suppl 6): 1375-9.

12 Schhnatter AR, Nicholich MJ, Bird MG. Determination of leukemogenic benzene exposure concentrations: refined analysis of the Pliofilm cohort. Risk Anal 1996; 16:833-40.

13 Townsend JC, OH MG, Fishbeck WA. Health exam findings among individuals occupationally exposed to benzene. J Occup Med 1978;20:543-8.

14 Ott MG, Townsend JC, Fishbeck WA, et al. Mortality among individual occupationally exposed to benzene. Arch Environ Health 1978;33:3-10.

15 Roush GJ, OHI MG. A study of benzene exposure versus urinary phenol levels. Am Ind Hyg Assoc J 1997;38:67-75.

16 Bond GG, McLaren EA, Baldwin CL, et al. An update of mortality among chemical workers exposed to benzene. Br J Ind Med 1986;43:685-91.

17 Marsh GM, Youk AO, Stone RA, et al. OCMAP-PLUS, a new program for the comprehensive analysis of occupational cohort data. J Occup Environ Med 1998;40:351-62. 
18 Marsh GM, Ehland J, Sefcik S. Mortality and population data system. Technical Report 2000. Pittsburgh, PA: Department of Biostatistics, University of Pittsburgh, 2000.

19 Breslow NE, Day NE. The design and analysis of cohort studies. Statistical methods in cancer research, Vol. II. IARC Scientific Publications No. 82. Lyon: International Agency for Research on Cancer; Oxford University Press, 1987.

20 Crump K. Risk of benzene-induced leukemia: a sensitivity analysis of the Pliofilm cohort with additional follow-up and new exposure estimates. J Toxicol Environ Health 1994;42:219-42.

21 Wong O, Raabe GK. A critical review of cancer epidemiology in studies of petroleum industry employees, with a quantitative meta-analysis by cancer site. Am J Ind Med 1989;15:283-310.
22 Raabe GK, Wong O. Leukemia mortality by cell type in petroleum workers with potential exposure to benzene. Environ Health Perspect 1996;104(suppl 6):1381-92.

23 Runion HE. Occupational exposures to potentially hazardous agents in the petroleum industry. Occup Med 1988;3:431-44.

24 Smith TJ, Hannond SK, Hallock M, et al. Health effects of gasoline exposure. I. Exposure assessment for U.S. distribution workers. Environ Health Perspect 1993;101(suppl 6):13-21.

25 Schnatter RS. Petroleum worker studies and benzene risk assessment. J Toxicol Environ Health 2000;61:433-7.

26 Crump K. Risks of benzene-induced leukemia predicted from the Pliofilm cohort. Environ Health Perspect 1996;104(suppl 6):1437-41 